\title{
Sexo oral e HIV entre homens que fazem sexo com homens
}

\author{
O ral sex and HIV among men \\ who have sex with men
}

\footnotetext{
1 Departamento de Saúde Bucal, Instituto de Infectologia Emílio Ribas. Av. Dr. Arnaldo 165, São Paulo, SP 01246-900, Brasil. serfu@macbbs.com.br
}

\begin{abstract}
Sexual transmission of the human immunodeficiency virus (HIV) continues to pose a public health problem worldwide. Men who have sex with men are still at differential risk of infection. Although there is evidence to claim that HIV can be transmitted by oral sex, the perception of this risk is ambiguous and relates paradoxically to behavior change. New models of risk perception must be developed in various areas of knowledge to obtain a fuller understanding of this phenomenon.

Key words Acquired Immunodeficiency Syndrome; Sex behavior; Male Homosexuality

Resumo A transmissão sexual do Vírus da Imunodeficiência Humana (HIV) representa um problema de saúde pública em todo o mundo, e homens que fazem sexo com homens encontram-se sob risco diferenciado para essa infecção. Ainda que exi stam evi dências suficientes para se afi rmar que o HIV pode ser transmiti do via sexo oral, a percepção desse risco é ambígua, e rel aciona-se de forma paradoxal com mudanças de atitude. Novos model os de percepção de risco devem ser desenvolvidos em diversas áreas de conhecimento para se alcançar compreensão aprofundada desse fenômeno.

Palavras-chave Síndrome delmunodeficiência Adquirida; Comportamento Sexual; Homossexualidade Masculina
\end{abstract}


AIDS, homens que fazem sexo com homens e sexo oral

Nas últimas duas décadas, a AIDS tem sido o problema relativo à saúde mais importante para o universo dos homens que fazem sexo com homens, e mesmo que tenha prontamente respondendo aos desafios colocados por essa epidemia, essa população ainda permanece vulnerável ao contágio pelo Vírus da I munodeficiência Humana (HIV).

No Brasil a transmissão sexual do HIV responde por grande parte dos casos de AIDS. Segundo o banco de dados do Ministério da Saúde (http:/ / www.aids.gov.br), entre 1990 e 1999, a via sexual esteve relacionada a contatos entre homens que fazem sexo com homens em $48 \%$ dos casos. Entre estes, $63,5 \%$ deles declararamse contaminados por exclusivo contato sexual entre homens. Entretanto, mesmo que a relevância da via sexual na transmissão do HIV seja indiscutivelmente reconhecida, o sexo oral nem sempre é percebido como prática sexual propriamente dita, ainda que em muitas comunidades represente uma das primeiras experiências sexuais entre jovens (Donovan \& Ross, 2000).

Atualmente existem evidências científicas suficientes para se concluir que o sexo oral pode ser uma via de transmissão para o HIV. Entretanto, os estudos conduzidos até a data presente ainda não dispõem de respostas precisas com respeito à quantificação e qualificação desse risco. Segundo uma revisão do Grupo Consultivo de Especialistas da Inglaterra, "a relativa escassez de casos de infecção pel o HIV atribuídos ao sexo oral é provavelmente influenciado pela escassez com que a exposição tenha ocorrido isoladamente, associada à tendência de se atribuir a transmissão do HIV a qualquer outra exposição de al to risco que possa ser identificada" (Hawkins et al., 2000).

Essas evidências são primariamente baseadas em relatos de casos clínicos, mas algumas também em estudos epidemiológicos. Entre eles, há que se remarcar o The Opti ons Project (CDC, 1999), assim como o de Rothemberg et al. (1998), por apontar a importância do reconhecimento desse risco, ao identificá-lo, e assim identificar a importância de seu potencial de contribuição no volume global da transmissão do HIV.

Os relatos de casos de transmissão oral não especificam exatamente qual foi o tipo de contato. As evidências sugerem que existe um significativo risco de soroconversão associado ao sexo oral receptivo (contato da cavidade bucal do sujeito em questão com o genital do parcei- ro). É razoável supor que o sexo oral receptivo com ejaculação na boca, oriunda de um parceiro infectado pelo HIV, envolveria exposição a uma grande quantidade de vírus. Ao lado dos diversos relatos da transmissão do HIV associada a sexo oral receptivo, existem também relatos via sexo oral insertivo, assim como associados a cunnilingus.

As evidências sugerem que o sexo oral parece ser a forma menos arriscada para a transmissão do HIV. Entretanto, parcerias homossexuais e heterossexuais normalmente realizam sexo oral conjuntamente com sexo genital e, assim, não é possível comparar-se os riscos desses dois tipos de atividade sexual. Isoladamente, o risco da transmissão pelo sexo oral pode ser aumentado na vigência de inflamação ou ulceração na boca, na vagina ou no ânus (Rothemberg et al., 1998).

O conjunto dessas evidências e os atuais conhecimentos do HIV e da cavidade bucal indicam que a transmissão do HIV via sexo oral é biologicamente plausível, e sustentam a conclusão epidemiológica que esse comportamento de risco é real, porém menor por essa forma de exposição do que pelas outras vias de sexo desprotegido (Hawkins et al., 2000). No entanto, ainda que muitos estudos tenham dimensionado essa prática de risco, a maneira como ele vem sendo percebido pela população e como vem sendo tratado pelas comunidades clínico-científicas reflete uma não assimilação do conhecimento disponível, revelando significativa carência de acuidade na percepção dessa via de transmissão.

\section{O risco - o que é e como é percebido}

O porquê das pessoas colocarem-se em risco, motivando-se ao sexo desprotegido, é uma questão complexa. Este procedimento é usualmente observado como um comportamento "patológico", inalcançável pela educação. Entretanto, nesse contexto, "patológico" baseia-se na epistemologia médica, que por vezes exclui motivações éticas individuais. Ao considerar a sobrevivência biológica como o principal objetivo da vida humana, essa epistemologia entende sexo desprotegido num mundo com AIDS como "patológico". Entretanto, se outros valores éticos são aceitos, valores que não a longevidade, mas aqueles relacionados com o conteúdo ou a qualidade de vida, então sexo desprotegido talvez não deva necessariamente ser considerado patológico (Odets, 1995).

Como descrito por Parker \& Terto (1998:119), “desde 1989, a pesqui sa soci ocomportamental 
realizada entre homens que fazem sexo com homens no Brasil vem registrando níveis relativamente al tos de con heci mento e informações sobre o HIV ea AIDS". No entanto, esses níveis relativamente al tos de conhecimento, paradoxalmente, relacionam-se a “...baixas taxas de mudança de comportamento" (Parker \& Terto, 1998:119).

A construção de modelos teóricos para a compreensão do crescimento da AIDS é de importância estrutural nesse contexto, pois não deixa de ser verdadeiro e atual o fato de que, mesmo com relativo alto nível de conhecimento e informação, indivíduos - em menor ou maior número - continuam a realizar práticas sexuais genitais e orais sem uso de barreiras protetoras contra o HIV (Souza et al., 1999). Mais e mais, a questão da prevenção ultrapassa os limites da epidemiologia, inserindo-se em contexto ético: se aos indivíduos é dado conhecer um determinado risco, se a elucidação a respeito desse risco é disponível, assim como as formas de se evitá-lo, e se esse risco pode representar a perda da vida individual e de outros, expor-se a ele ou fazer que outros se exponham representa um paradoxo para educadores, clínicos e cientistas.

No entanto, se ao lado desse aparente paradoxo, pudermos pensar que a percepção de risco pode estar estreitamente relacionada a formas de proteção contra um determinado mal, e que essas formas de proteção são muitas vezes reinterpretadas e readaptadas pelo sujeito, na subjetividade da sua compreensão, então um novo campo de reflexão pode ser estabelecido.

As ciências sociais vêm apontando a complexidade dos fatores ligados à administração dos riscos ligados à transmissão do HIV. Sob essa ótica, esses trabal hos observam como diferentes contextos e diversas interações sociais e individuais podem influenciar os comportamentos e as práticas sexuais. O que pode ser decisivo nesse contexto é o fato desses trabaIhos não apontarem necessariamente para um comportamento irracional mas, antes disso, para uma outra forma de racionalidade (Davies et al., 1993).

A respeito dessa questão, o trabalho realizado por Mendès-Leite (1995), é particularmente esclarecedor, ao descrever o fenômeno que ele chamou de proteções imaginárias.

Esse fenômeno mostra que a maioria dos indivíduos conhece a necessi dade da administração dos riscos, está convencida da sua importância e realiza práticas preventivas determinadas. No entanto, muitas vezes esses indivíduos procedem a uma reapropriação das normas de prevenção, deslocando seu sentido para outra perspectiva, ainda que, sob a ótica deles, o objetivo preventivo permaneça o mesmo.

O ator social recorre a uma manipulação simbólica das práticas preventivas, ao tornálas mais próximas de seu quadro cognitivo, o que lhe permite readaptá-las, guardando a impressão de não se colocar sob risco. É o caso do indivíduo que, no lugar de utilizar sistematicamente o preservativo em encontros aonde haja penetração, usa-o segundo a aparência ou o estilo de vida de seus parceiros sexuais. Se, para a epidemiologia, tal tática pode parecer irracional pela sua ineficácia, ela é totalmente lógica para o indivíduo. Na realidade, na sua própria maneira, o que o indivíduo faz aqui é utilizar um dos principais mandamentos preventivos: evitar contatos desprotegidos com uma pessoa contaminada (Mendès-Leite, 1995).

Sendo uma construção cultural, a prevenção (e os comportamentos que ela implica) não pode ser estudada senão sob a visão do conjunto das representações da doença, do corpo, da infelicidade e do mundo ao qual os indivíduos estão inseridos. Em se tratando da transmissão de uma doença pela via sexual, as representações do imaginário social sobre a sexualidade (sexo, gênero, categorias e orientações sexuais, estilo de vida e de sexualidade, etc.) são também de grande importância (Mendès-Leite, 1995).

É por isso que os indivíduos vão interpretar os preceitos preventivos segundo o seu quadro cognitivo sócio-cultural, dando-Ihes um sentido que tornará possível colocá-los em prática. É um mecanismo perfeitamente racional, que não nega a importância das atitudes prospectivas para se prevenir contra a doença. Muito pelo contrário, é exatamente por conhecê-los e por dar crédito a esses preceitos que os indivíduos irão deles se apropriar e lhes dar sentido próprio, mesmo se aos olhos dos outros o conteúdo "racional" possa parecer, no mínimo, paradoxal (Mendès-Leite, 1995).

Os atores sociais também tentam fazer prevalecer suas preferências e práticas sexuais com uma lógica preventiva, mas, segundo o mesmo raciocínio, readaptam essa lógica de acordo com seus gostos e inclinações. Eles se "aproveitam", por exemplo, do fato de que o discurso sobre a importância do preservativo na felação seja muito ambíguo, para escolher exatamente a favor daquilo que eles preferem. Essa credulidade é semelhante àquela de pessoas que, por diminuírem o número de seus amantes, presumem poder negligenciar a utilização sistemática dos preservativos (Mendès-Leite, 1995).

E é por isso que esses paradoxos, desde sempre inseridos no contexto epidemiológico, 
devem também ser compreendidos por outras áreas de conhecimento, como a antropologia, a psicologia e a sociologia, na medida em que requerem reflexão ética aprofundada a respeito do significado da liberdade individual nas sociedades humanas.

Se essa liberdade é ilustrada nesses paradoxos, são corretos os argumentos de Wolfe (2001:
213), ao afirmar que "sem total liberdade moral, todas as outras formas de liberdade são ilusórias. Despojados dos aspectos eróticos de nossa natureza, nós não podemos ser livres, não importa o quanto acreditamos ser, em nosso trabalho, nossas políticas - ou mesmo, estranhamente- nas nossas vidas sexuais".

\section{Referências}

CDC (Centers for Disease Control and Prevention), 1999. Primary HIV Infection Associated with Oral Transmission. Atlanta: CDC-NCHSTP Division of HIV/AIDS Prevention.

DAVIES, P. M.; HICKSON, F. C. I. \& WEATHERBURN, P., 1993. Sex, Gay Men and AIDS. London: Routledge Falmer Press.

DONOVAN, B. \& ROSS, M. W., 2000. Preventing HIV: determinants of sexual behavior. Lancet, 355: 1897-1901.

HAWKINS, D. A.; JEFFRIES, D. J.; CHALLACOMBE, S. J.; EVANS, B. \& TURNBULL, S., 2000. Review of the Evidence on Risk of HIV Transmission Associated with Oral Sex. London: UK Chief Medical Officers' Expert Advisory Group on AIDS.

MENDÈS-LEITE, R., 1995. Identité et altérité - Protections imaginaires et symboliques face au sida. Gradhiva, 18:93-103.

ODETS, W., 1995. In the Shadow of the Epidemic - Being HIV-Negative in the Age of AIDS. Durham: Duke University Press.

PARKER, R. \& TERTO, V., 1998. Entre Homens - Homossexualidade e Aids no Brasil. Rio de Janeiro: Editora A4 Mãos Ltda.

ROTHEMBERG, R. B.; SCARLETT, M.; DEL RIO, C.; REZNIK, D. \& O'DANIELS, C., 1998. Oral transmission of HIV. AIDS, 12:2095-2105.

SOUZA, C. T.; BASTOS, F. I.; LOWNDES, C. M.; SZWARCWALD, C. L.; SANTOS, E. M.; CASTILHO, E. A. \& SUTM OLLER, F., 1999. Perception of vulnerability to HIV infection in a cohort of homosexual/bisexual men in Rio de Janeiro, Brazil. Oswaldo Cruz Foundation STD/HIV Prevention Group. AIDS Care, 11:567-579.

WOLFE, A., 2001. Moral Freedom. New York/London: W. W. Norton \& Company.

Recebido em 8 de abril de 2002

Versão final reapresentada em 23 de setembro de 2003

Aprovado em 30 de setembro de 2003 